\title{
Keterampilan Berpikir Kritis IPA Siswa SD: Brain Based Learning (BBL) dan Problem Based Learning (PBL)
}

\author{
Farida Nur Kumala ${ }^{1}$, Karvita Firdayani ${ }^{2}$, Muhammad Nur Hudha ${ }^{3}$ \\ PGSD Universitas Kanjuruhan Malang \\ SDN Wonokirti Kecamatan Tosari Kabupaten Pasuruan
}

\begin{abstract}
Abstrak:
Penelitian ini bertujuan untuk mengetahui kemampuan berpikir kritis siswa yang menggunakan model pembelajaran BBL dan PBL. Subyek penelitian ini adalah siswa kelas V SD sejumlah 56 siswa dengan instrumen yang digunakan adalah tes keterampilan berpikir kritis dengan analisis data menggunakan uji-t. Hasil penelitian menunjukkan bahwa keterampilan berpikir IPA siswa yang menggunakan model pembelajaran BBL lebih tinggi daripada yang menggunakan model PBL ditunjukkan dengan nilai rata rata 83 untuk model pembelajaran BBL dan 69 untuk moddel pembelajaran PBL ditunjukkan dengan nilai $\mathrm{t}$ hitung > t tabel $(5,139>2,003)$ dan taraf signifikasi 0,000 yang nilainya lebih besar dari $0,05(0,000<0,05)$ (sig 0,05). BBL menyediakan pembelajaran yang membuat lebih rileks yang dipadukan dengan kegiatan pembelajaran berbasis masalah, ketika pembelajaran dilakukan secara rileks, penuh arti dan secara aktif maka otak akan bekerja lebih optimal sehingga siswa merasa lebih nyaman dan termotivasi di kelas.
\end{abstract}

Kata Kunci : Kemampuan Berpikir Kritis, Model Pembelajaran BBL, Model Pembelajaran PBL

\section{Abstract:}

This study aims to determine the critical thinking skills of students use BBL and PBL learning models. The subjects of this study were 5 grade elementary school 56 students, using the critical thinking skills test with data analysis using t-test. The results showed that the science thinking skills of students who used the BBL learning model were higher than those using the PBL model indicated by the average value of 83 for the $B B L$ learning model and 69 for the PBL learning model indicated by the value of $t$ count $\rangle t$ table $(5,139\rangle$ $2,003)$ and significance level of 0,000 whose value is greater than $0.05(0.000<0.05)$ (sig 0.05). BBL provides learning that makes more relaxation combined with problem-based activities, makes learning more optimal, and is more active with the brain that will work more optimally.

Keywords: Critical Thinking Skills, BBL Learning Model, PBL Learning Model

\section{PENDAHULUAN}

Kemampuan berpikir kritis dalam kehidupan sehari - hari biasanya dimanfaatkan untuk memutuskan menerima atau menolak suatu opini secara cerdas (Bassham, Irwin, Nardone, \& Wallace, 2011). Kemampuan berpikir kritis penting diajarkan dalam kehidupan sehari hari, agar kelak siswa mampu memtuskan dan menentukan keputusan dalam hidupnya secara tepat dan cerdas.
Berpikir kritis merupakan sebuah proses terorganisasi yang memungkinkan siswa mengevaluasi bukti, asumsi, logika, dan bahasa yang mendasari pernyataan orang lain. Berpikir kritis (critical thinking) adalah kegiatan berpikir yang dilakukan dengan mengoperasikan potensi intelektual untuk menganalisis sehingga dapat mengambil keputusan secara tepat (Ngalimun, 2017:143). Setiap orang memiliki kemampuan untuk menjadi seorang pemikir kritis yang 
JIP, Vol.8, No. 2, Edisi Agustus 2018, Hal: 53-59 Farida Nur Kumala ${ }^{1}$, Karvita Firdayani ${ }^{2}$, Muhammad Nur Hudha ${ }^{3}$

andal karena otak manusia secara konstan berusaha memahami pengalaman. Pentingnya kemampuan berpikir ini menjadi alasan untuk dapat diajarkan pada kepada siswa melalui pembelajaran (Pieterse etal, 2016) dimana guru menggunakan metode, cara mengajar keterampilan berpikir (Vong dan Kaewurai, 2016) dan bahan kurikulum yang tepat (Gadzella \& Masten, 1998; Halpern, 1993; McMillan, 1987). Dalam pembelajaran kemampuan berpikir, siswa harus mampu berkomunikasi secara efektif dan memecahkan masalah secara efisien serta mengharuskan siswa untuk terlibat secara aktif dalam keterampilan memecahkan masalah (Zivkovic,2016) dan mengoptimalkan fungsi otak (Jensen, 2011).

Beberapa peneliti menjelaskan hubungan antara fungsi otak dan praktik pendidikan. Teori belajar berbasis otak berfokus pada penggunaan penelitian tentang bagaimana otak bekerja dan guru dapat menggunakan cara atau pemahaman ini untuk membantu siswa belajar secara efisien. Menyajikan pembelajaran yang efektif dan bermakna sehingga menyeimbangkan potensi otak anak (Jensen, 2011).

Menurut Caine dan Caine (dalam Devi, 2016) menyatakan bahwa otak bekerja menggunakan pendekatan holistik yang menekankan pada pentingnya bagaimana otak belajar untuk menghasilkan pembelajaran yang melatih pemahaman konsep sehingga bermakna. Pembelajaran yang bermakna adalah pembelajaran yang mengaktifkan otak dengan berdasarkan koneksi dalam pikirannya.

Salah satu pembelajaran yang bisa mengoptimalkan potensi dan fungsi otak siswa yaitu pembelajaran berbasis otak (Brain Based Learning). Pembelajaran berbasis otak ini menyajikan pembelajaran selain bermakna juga pembelajaran yang efektif. Pembelajaran yang efektif adalah pembelajaran yang menyenangkan dan bisa menyeimbangkan potensi otak anak (otak kanan dan otak kiri) (Jensen, 2011). Strategi utama yang dapat dikembangkan dalam implementasi pembelajaran berbasis otak yaitu menciptakan lingkungan belajar yang menyenangkan dan (Sapa'at,2009) menantang kemampuan berpikir siswa dengan melakukan senam otak Brain Gym (Fajriati, 2017: 5).

Model pembelajaran Brain Based Learning menciptakan situasi pembelajaran yang aktif dan bermakna, membantu siswa untuk belajar lebih efektif (Yagliocu, 2014); meningkatkan prestasi dan retensi pemahaman yang lebih baik (Haghighi, 2013).

Model Brain Based Learning dapat meningkatkan kemampuan berpikir kritis dan respon yang positif kepada siswa. Serta siswa dalam pembelajaran BBL menunjukkan hasil yang lebih baik daripada menggunakan pembelajaran secara langsung. (Karunia, 2014).

Pada model BBL (Brain Based Learning) menuntut peserta didik untuk lebih aktif dalam pembelajaran. Siswa dituntut 
JIP, Vol.8, No. 2, Edisi Agustus 2018, Hal: 53-59 Farida Nur Kumala ${ }^{1}$, Karvita Firdayani ${ }^{2}$, Muhammad Nur Hudha ${ }^{3}$

untuk mampu mengidentifikasi berbagai masalah yang perlu dipelajari lebih jauh (investigation). Tahu di mana harus mencari sumber-sumber belajar yang berkaitan dengan masalah yang dialami. Mampu menentukan prioritas dan merancang penelusuran sumber belajar. Menghubungkan informasi yang telah terkumpul dengan topik bahasan yang sedang dipelajarinya. Selain itu, pembelajaran dengan model pembelajaran Brain Based Learning sebagai pembelajaran yang berpusat pada peserta didik (Mustiada, 2007:2).

Selain model pembelajaran Brain Based Learning Model lain yang dapat digunakan adalah model Problem Based Learning. Problem Based Learning (PBL) adalah model pembelajaran yang melatih dan mengembangkan kemampuan untuk menyelesaikan masalah. Berorientasi pada masalah otentik dari kehidupan aktual siswa untuk merangsang kemampuan berfikir tingkat tinggi. Kondisi yang harus dipelihara adalah suasana kondusif, terbuka, negosiasi, demokratis, suasana nyaman dan menyenangkan agar siswa dapat berpikir optimal Ngalimun (2017: 330). Esensi pembelajaran berbasis masalah adalah pembelajaran yang menyuguhkan berbagai situasi masalah yang autentik dan bermakna kepada peserta didik agar mereka menyelidikinya. dengan belajar berpikir kritis, keterampilan memecahkan masalah dan memperoleh pengetahuan serta konsep esensial dari materi pembelajaran (Suprijono, 2016: 202).

Pembelajaran berbasis masalah merupakan pembelajaran yang efektif dan mempengaruhi kemampuan belajar siswa terutama untuk retensi pengetahuan jangka panjang serta mudah untuk diaplikasikan (Goh dan Dewey, 2016), siswa menjadi aktif dalam pembelajaran, bertanggung jawab, mampu mengatasi beberapa permasalahan dan mengajarkan kemampuan berpikir kritis untuk melakukan analisisi dan pemecahan masalah dunia nyata ( Arlahlah, 2016; Ghou, 2014), mandiri, mengembangkan keterampilan meneliti dan kemampuan memecahkan masalah kontekstual siswa secara logis (Suprijono, 2016:203; Khairuntika, 2015; Aziz, dkk 2014:)

Berdasarkan hal tersebut peneliti menggunakan 2 model yaitu model pembelajaran Brain Based Learning dan model pembelajaran Problem Based Learning untuk mencoba membandingkan pembelajaran yang efektif untuk mengembangkan kemampuan berpikir kritis siswa

\section{METODE}

Penelitian ini menggunakan pendekatan kuantitatif dengan rancangan penelitian Nonequivalent Control Group Design. Adapun pola desain penelitian ini adalah sebagai berikut:

\begin{tabular}{|lll|}
\hline $\mathrm{O}_{1}$ & $\mathrm{X}$ & $\mathrm{O}_{2}$ \\
$\mathrm{O}_{3}$ & & $\mathrm{O}_{4}$ \\
\hline
\end{tabular}


JIP, Vol.8, No. 2, Edisi Agustus 2018, Hal: 53-59

Farida Nur Kumala ${ }^{1}$, Karvita Firdayani ${ }^{2}$, Muhammad Nur Hudha ${ }^{3}$

Keterangan:

$\mathrm{O}_{1} \quad$ : nilai pretest kelas eksperimen

$\mathrm{O}_{2} \quad$ :nilai postest kelas eksperimen

$\mathrm{X} \quad$ : pembelajaran dengan menggunakan model pembelajaran Brain Based Learning

$\mathrm{O}_{3} \quad$ : nilai pretest kelas kontrol

$\mathrm{O}_{4} \quad$ : nilai postest kelas kontrol

Subyek penelitian adalah siswa kelas 5 yang berjumlah 56 siswa SD Wonokitri Kecamatan Tosari Kabupaten Pasuruan .Instrumen yang digunakan pada penelitian ini adalah instrumen tes kemampuan berpikir kritis dengan kisi instrumen ditunjukkan pada tabel 1.1:

Tabel 1.1 Tabel indikator berpikir kritis

\begin{tabular}{|c|c|c|}
\hline No & Kelompok & Indikator \\
\hline \multirow[t]{3}{*}{1} & $\begin{array}{l}\text { Memberikan } \\
\text { penjelasan }\end{array}$ & $\begin{array}{l}\text { 1. Memfokuskan } \\
\text { pertanyaan. }\end{array}$ \\
\hline & sederhana & 2. Menganalisis argumen \\
\hline & & $\begin{array}{l}\text { 3. Bertanya dan } \\
\text { menjawab pertanyaan }\end{array}$ \\
\hline \multirow[t]{2}{*}{2} & $\begin{array}{l}\text { Membangun } \\
\text { keterampilan } \\
\text { dasar }\end{array}$ & $\begin{array}{l}\text { 4. Mempertimbangkan } \\
\text { apakah sumber dapat } \\
\text { dipercaya }\end{array}$ \\
\hline & & $\begin{array}{l}\text { 5. Mengobservasi dan } \\
\text { mempertimbangkan } \\
\text { laporan observasi }\end{array}$ \\
\hline \multirow[t]{3}{*}{3} & Menyimpulkan & $\begin{array}{l}\text { 6. Mengdedukasi dan } \\
\text { mempertimbangkan } \\
\text { hasil hasil deduksi }\end{array}$ \\
\hline & & $\begin{array}{l}\text { 7. Menginduksi dan } \\
\text { mempertimbangkan } \\
\text { hasil induksi }\end{array}$ \\
\hline & & 8. Membuat \\
\hline
\end{tabular}

\begin{tabular}{|c|c|c|}
\hline & & $\begin{array}{l}\text { menentukan hasil } \\
\text { pertimbangan }\end{array}$ \\
\hline \multirow[t]{2}{*}{4} & $\begin{array}{l}\text { Memberikan } \\
\text { penjelasan } \\
\text { lanjut }\end{array}$ & $\begin{array}{l}\text { 9. Mendefinisikan istilah } \\
\text { dan } \\
\text { mempertimbangkan } \\
\text { suatu definisi }\end{array}$ \\
\hline & & $\begin{array}{l}\text { 10. Identifikasi asumsi- } \\
\text { asumsi }\end{array}$ \\
\hline \multirow[t]{2}{*}{5} & $\begin{array}{l}\text { Mengatur } \\
\text { strategi dan }\end{array}$ & $\begin{array}{l}\text { 11. menemukan } \\
\text { tindakan }\end{array}$ \\
\hline & kritik & $\begin{array}{l}\text { 12. Berinteraksi dengan } \\
\text { orang lain }\end{array}$ \\
\hline
\end{tabular}

Analisis data menggunakan independent Sample t-test dengan uni prasyarat menggunakan uji normalitas dan homogenitas. Adapun rumusan perhitungan Independent Sample t-test adalah sebagai berikut :

$$
t=\frac{\bar{x} 1-\bar{x} 2}{S g \sqrt{\left(\frac{1}{n 1}+\frac{1}{n 2}\right)}}
$$

(Sugiyono, 2015: 273)

Di mana $\mathrm{t}$ adalah $\mathrm{t}$ hitung. Dengan kriteria pengujian $\mathrm{H}_{\mathrm{o}}$ diterima apabila $\mathrm{t}_{\text {hitung }}<$ $\mathrm{t}_{\text {tabel. }} \quad \mathrm{T}_{\text {tabel }}=\mathrm{t}_{1^{-}}{ }^{1} / 2 \quad \alpha$ didapat dari daftar distribusi $\mathrm{t}$ dengan derajat kebebasan $\mathrm{df}=\mathrm{n}-2$. Dengan taraf signifikan $5 \%$ dan $\mathrm{H}_{\mathrm{o}}$ ditolak. dengan kriteria pengujian sebagai berikut:

a. Ho diterima jika $t_{\text {hitung }}>t_{\text {tabel }}$

b. Ho ditolak jika $t_{\text {hitung }}<t_{\text {tabel }}$

dengan Rumusan Hipotesis 1:

H0 : Tidak terdapat perbedaan keterampilan berpikir kritis IPA antara siswa yang menggunakan model Pembelajaran 
JIP, Vol.8, No. 2, Edisi Agustus 2018, Hal: 53-59 Farida Nur Kumala ${ }^{1}$, Karvita Firdayani ${ }^{2}$, Muhammad Nur Hudha ${ }^{3}$

Brain Based Learning dan model Pembelajaran problem based learning.

H1 : Terdapat perbedaan keterampilan berpikir kritis IPA antara siswa yang menggunakan model Pembelajaran Brain Based Learning dan model pembelajaran Problem Based Learning.

\section{HASIL DAN PEMBAHASAN}

Berdasarkan hasil penelitian ditunjukkan pada tabel 1.2 berikut ini:

Tabel 1.2 Tabel hasil penelitian

\begin{tabular}{llc}
\hline Kelas & Model & Rata- rata \\
\hline Eksperimen & Brain Based Learning & 83 \\
\hline Kontrol & Problem Based Learning & 69 \\
\hline
\end{tabular}

Berdasrkan hasil penelitian dapat ditunjukkan bahwa, kelas eksperimen mendapatkan nilai rata-rata lebih tinggi dibandingkan dengan nilai kelas kontrol. Hasil penelitian ini didukung dengan hasil nilai uji $\mathrm{t}$ yang ditunjukkan oleh tabel 1.3.

Tabel 1.3 Tabel uji t

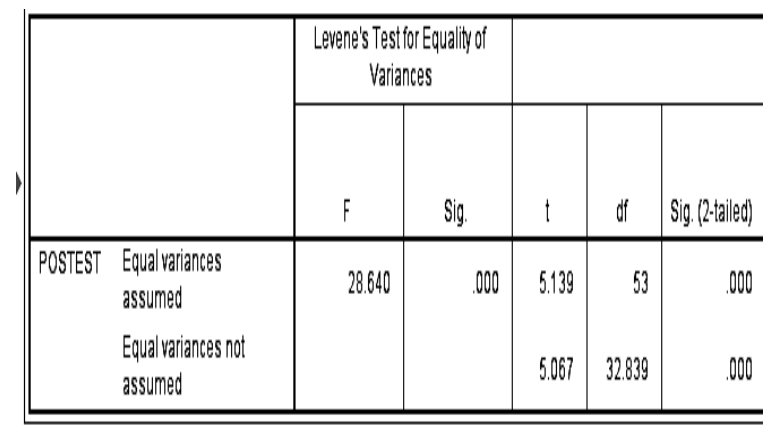

Berdasarkan hasil uji $\mathrm{t}$ (independent sampel test) pada tabel 1.3, maka diperoleh (df) n-2 atau 55-2=53. Hasil yang diperoleh dari t tabel $(5,139>2,003)$ dan taraf signifikasi
0,000 yang nilainya lebih besar dari 0,05 $(0,000<0,05)(\operatorname{sig} 0,05)$. Dengan demikian H0 ditolak artinya bahwa terdapat perbedaan hasil keterampilan berpikir kritis IPA siswa yang diajarkan menggunakan model pembelajaran Brain Based Learning pada kelas V SDN Wonokitri Kecamatan Tosari Kabupaten Pasuruan.

Perbedaan hasil penelitian disebabkan oleh nilai keterampilan berpikir kritis siswa kelas eksperimen lebih tinggi daripada kelas kontrol karena dalam kelas eksperimen menggunakan model pembelajaran Brain Based Learning. Model pembelajaran Brain Based Learning dapat mengaktifkan cara kerja otak, menciptakan lingkungan belajar yang positif dan menyenangkan (Jensen, 2011:132). Pada umumnya siswa memiliki respon positif terhadap pembelajaran IPA dengan menggunakan model pembelajaran Brain Based Learning yaitu terhadap penyajian materi, proses pembelajaran dan evaluasi pembelajaran melalui Brain Based Learning.

Peningkatan kemampuan berpikir kritis IPA siswa yang mendapatkan pembelajaran Brain Based Learning lebih baik dari pada siswa yang mendapat pembelajaran dengan menggunakan model pembelajaran Problem Based Learning (Karunia, 2014; Mustiada, 2014; Wulandarai 2014).

Berdasarkan penelitian ini dapat disimpulkan bahwa terdapat perbedaan antara pembelajaran yang menggunakan model 
JIP, Vol.8, No. 2, Edisi Agustus 2018, Hal: 53-59 Farida Nur Kumala ${ }^{1}$, Karvita Firdayani ${ }^{2}$, Muhammad Nur Hudha ${ }^{3}$

pembelajaran Brain Based Learning dan Problem Based Learning. Hal ini menunjukkan bahwa model pembelajaran Brain Based Learning dapat digunakan sebagai model pembelajaran yang bervariatif. Kelebihan model pembelajaran brain based learning adalah pembelajaran yang sangat efektif dengan mengoptimalkan hasil kerja otak (Thomas:2014). Desain lingkungan belajar yang nyaman, menyenangkan dan menantang yang akan menciptakan lingkungan yang bermakna. sehingga dapat meningkatkan prestasi siswa (Hidayah, $2015: 25$ ).

\section{KESIMPULAN}

Ada perbedaan keterampilan berpikir kritis IPA siswa yang menggunakan model pembelajaran Brain Based Learning dan model pembelajaran Problem Based Learning di kelas V SDN Wonokitri Kecamatan Tosari Kabupaten Pasuruan.

\section{DAFTAR PUSTAKA}

Alrahlah, A. (2016). How Effective The Problem-Based Learning (Pbl) In Dental Education. A critical review. The Saudi Dental Journal (2016) 28, 155-161

Aziz, M. S., Zain, A. N., Samsudin, M. A. B., Saleh.S.B. 2014 . The Effects of ProblemBased Learning on Self-Directed Learning Skills among Physics Undergraduates. International Journal of Academic Research in Progressive Education and Development 3 (1) (online

Bassham, G., Irwin, W., Nardone, H., \& Wallace, J. M. (2011). Critical thinking: A student's introduction (4th ed.). New York, NY: McGraw Hill.
Devi, P. 2016. Brain Based Learning a New Instructional Approach. 5(2), (online).(http://www.worldwidejournals.c om)

Fajriati, I. S. 2017. Pengaruh Penerapan Metode Pembelajaran Brain Based Learning Berbantuan Brain Gym Terhadap Hasil Belajar Peserta Didik. Jurnal Biotek 5 (1), (online). (http://journal.uin.alaudin.ac.id)

Gadzella, B. M., \& Masten, W. G. (1998). Critical Thinking And Learning Processes For Students In Two Major Fields. Journal of Instructional Psychology, 25(4), $256 \mathrm{e} 261$.

Haghighi, M. (2013). The Effect Of BrainBased Learning On Iranian Efl Learner's Achievement And Retention. Procedia Social and Behavioral Sciences 70 ( 2013 ) $508-516$

Halpern, D. F. (1993). Assessing The Effectiveness Of Critical Thinking Instruction. The Journal of General Education, 42(4), 239e254.

Hidayah, L. 2015. Efektifitas Model Pembelajaran Brain Based Learning (BBL) dengan Pendekatan Saintifik Berbantu Alat Peraga Sederhana Terhadap Hasil Belajar Matematika Peserta Didik Kelas VIII Pada Materi Garis Singgung Lingkaran. Universitas Islam Negeri Walisongo Semarang. (Online)(http://eprints.walisongo.ac.id)

Jensen, E. (2011). Pemelajaran Berbasis Otak. Jakarta: Indeks.

Khairuntika. 2015. Implementasi Model Problem Based Learning. Seminar Nasional Matematika Dan Pendidikan Matematika. 339 (49), (online). (http://www.scribd.com.)

Mat, S. (2012). Model Of Problem-Based Learning Using Systems Approach. 
JIP, Vol.8, No. 2, Edisi Agustus 2018, Hal: 53-59 Farida Nur Kumala ${ }^{1}$, Karvita Firdayani ${ }^{2}$, Muhammad Nur Hudha ${ }^{3}$

Procedia - Social and Behavioral Sciences 60 ( 2012 ) $541-545$.

McMillan, J. H. (1987). Enhancing College Student's Critical Thinking: A Review Of Studies. Research in Higher Education, 26(1), 3e29.

Murti, B. 2009. Peningkatan Kemampuan Berpikir Kritis Dalam Pembelajaran IPA Melalui Model Problem Based Learning (PBL) Pada Peserta Didik Kelas VIII SMP Negeri 1 Turi . E-journal pendidikan IPA 1 (htttp://journal.student.uny.ac.id)

Mustiada, I. G. A. M., Agung, A. A. G., Antari, N. N. M. 2014. Jurnal Mimbar PGSD Universitas Pendidikan Ganesha. Pengaruh Model Pembelajaran BBL (Brain Based Learning) Bermuatan Karakter Terhadap Hasil Belajar IPA. (online) (http://ejournal.undiksa.ac.id)

Ngalimun. 2017. Strategi Pendidikan. Yogyakarta: Parama Ilmu.

Pieterse, T. Et.al (2016). Critical Thinking Ability Of 3rd Year Radiography. he alth s a ge sondheid 21 ( 2016 ) 381 - 390 .

Sapa'at. 2009. "Brain Based Learning", http://matematika. upi. Edu / index.php/brainbased -learning.

Sugiyono, 2015. Metode Penelitian Pendidikan. Alfabeta: Bandung.

Suprijono, A. 2016. Model-model pembelajaran Emansipatoris.Yogyakarta: Pustaka Pelajar

Supriyono, (2013). Pengembangan Bahan Ajar Berbasis Konstruktivis Pada Mata Kuliah Telaah Kurikulum Fisika II (Tkf II) untuk Mahasiswa Kelas Internasional Di Jurusan Fisika UNESA. Jurnal Pendidikan Fisika dan Aplikasinya (JPFA) Vol 3 No 1, 31-40.
Vong, S.A dan Kaewurai, W.(2017). Instructional Model Development To Enhance Critical Thinking And Critical Thinking Teaching Ability Of Trainee Students At Regional Teaching Training Center In Takeo Province, Cambodia. Kasetsart Journal of Social Sciences 38 (2017) 88e95.

Wulandari, A. D. 2014. Brain Based Learning Untuk Meningkatkan Kemampuan Berpikir Kritis dan Hasil Belajar Siswa. Chemistry In Education 3 (1). (online) http://journal.unnes.ac.id/sju/index.php/ch emined

Yagcioglu, O. 2014. The Advantages Of Brain Based Learning In Elt Classes. Procedia Social and Behavioral Sciences 152 ( 2014 ) $258-262$

Yew, E.H.J and Goh, K. (2016). ProblemBased Learning: An Overview of its Process and Impact on Learning. Health ProfessionsEducation2(2016)75-79

Zivkovic, S. (2016). A Model of Critical Thinking as an Important Attribute for Success in the 21st Century. Procedia Social and Behavioral Sciences 232 ( 2016 ) $102-108$. 